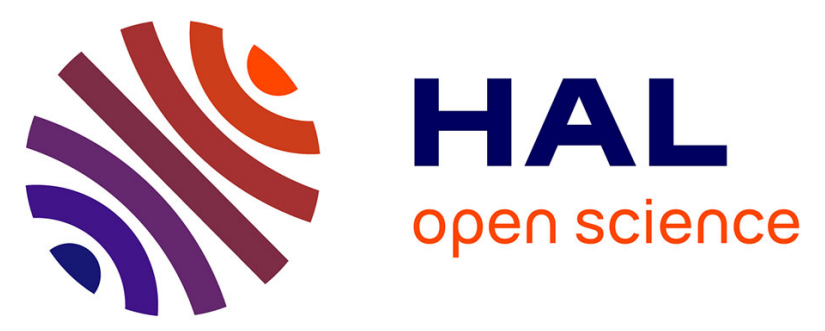

\title{
Effects of vitamin C, vitamin E, zinc gluconate, and selenomethionine supplementation on muscle function and oxidative stress biomarkers in patients with facioscapulohumeral dystrophy: A double-blind randomized controlled clinical trial
}

Emilie Passerieux, Maurice Hayot, Audrey Jaussent, Gilles Carnac, Fares Gouzi, Fabien Pillard, Marie-Christine Picot, Koen Böcker, Gerald Hugon, Joel Pincemail, et al.

\section{To cite this version:}

Emilie Passerieux, Maurice Hayot, Audrey Jaussent, Gilles Carnac, Fares Gouzi, et al.. Effects of vitamin $\mathrm{C}$, vitamin $\mathrm{E}$, zinc gluconate, and selenomethionine supplementation on muscle function and oxidative stress biomarkers in patients with facioscapulohumeral dystrophy: A double-blind randomized controlled clinical trial. Free Radical Biology and Medicine, 2015, 81, pp.158 - 169. 10.1016/j.freeradbiomed.2014.09.014 . hal-01679192

\author{
HAL Id: hal-01679192 \\ https://hal.science/hal-01679192
}

Submitted on 9 Jan 2018

HAL is a multi-disciplinary open access archive for the deposit and dissemination of scientific research documents, whether they are published or not. The documents may come from teaching and research institutions in France or abroad, or from public or private research centers.
L'archive ouverte pluridisciplinaire HAL, est destinée au dépôt et à la diffusion de documents scientifiques de niveau recherche, publiés ou non, émanant des établissements d'enseignement et de recherche français ou étrangers, des laboratoires publics ou privés. 
Original Contribution

\title{
Effects of vitamin C, vitamin E, zinc gluconate, and selenomethionine supplementation on muscle function and oxidative stress biomarkers in patients with facioscapulohumeral dystrophy: A double-blind randomized controlled clinical trial
}

\author{
Emilie Passerieux ${ }^{a}$, Maurice Hayot ${ }^{b}$, Audrey Jaussent ${ }^{c}$, Gilles Carnac ${ }^{a}$, Fares Gouzi ${ }^{b}$, \\ Fabien Pillard ${ }^{\mathrm{d}}$, Marie-Christine Picot ${ }^{\mathrm{e}}$, Koen Böcker ${ }^{\mathrm{f}}$, Gerald Hugon ${ }^{\mathrm{a}}$, Joel Pincemail ${ }^{\mathrm{g}}$, \\ Jean O. Defraigne ${ }^{g}$, Theo Verrips ${ }^{\text {h }}$, Jacques Mercier ${ }^{b}$, Dalila Laoudj-Chenivesse ${ }^{\mathrm{b}, *}$ \\ ${ }^{a}$ University of Montpellier 1 and 2, INSERM Unit 1046, Montpellier, France \\ b University of Montpellier 1 and 2, INSERM Unit 1046, Montpellier, France and Department of Clinical Physiology, University Hospital, Montpellier, France \\ ${ }^{\mathrm{c}}$ Department of Biostatistics and Epidemiology, University Hospital of Montpellier, Montpellier, France \\ ${ }^{\mathrm{d}}$ Department of Respiratory Exploration and Department of Sports Medicine, Larrey University Hospital, Toulouse CEDEX, France \\ e Department of Biostatistics and Epidemiology, University Hospital, Montpellier, France and CIC 1001-INSERM \\ ${ }^{\mathrm{f}}$ Alan Turing Institute Almere, The Netherlands \\ ${ }^{g}$ Department of cardiovascular Surgery and Department of CREDEC, University Hospital of Liege, Belgium \\ ${ }^{\text {h }}$ Utrecht University, Department of Biology, The Netherlands
}

Keywords:

Facioscapulohumeral muscular

dystrophy (FSHD)

Oxidative stress

Antioxidants

Radical oxygen species

Physical performance

\begin{abstract}
A B S T R A C T
Facioscapulohumeral muscular dystrophy (FSHD) is an autosomal dominant disease characterized by progressive weakness and atrophy of specific skeletal muscles. As growing evidence suggests that oxidative stress may contribute to FSHD pathology, antioxidants that might modulate or delay oxidative insults could help in maintaining FSHD muscle function. Our primary objective was to test whether oral administration of vitamin C, vitamin E, zinc gluconate, and selenomethionine could improve the physical performance of patients with FSHD. Adult patients with FSHD $(n=53)$ were enrolled at Montpellier University Hospital (France) in a randomized, double-blind, placebo-controlled pilot clinical trial. Patients were randomly assigned to receive $500 \mathrm{mg}$ vitamin C, $400 \mathrm{mg}$ vitamin E, $25 \mathrm{mg}$ zinc gluconate and $200 \mu \mathrm{g}$ selenomethionine $(n=26)$, or matching placebo $(n=27)$ once a day for 17 weeks. Primary outcomes were changes in the two-minute walking test (2-MWT), maximal voluntary contraction, and endurance limit time of the dominant and nondominant quadriceps $\left(\mathrm{MVC}_{\mathrm{QD}}, \mathrm{MVC}_{\mathrm{QND}}, \mathrm{T}_{\text {limeD }}\right.$, and $\mathrm{T}_{\text {limeND, }}$, respectively) after 17 weeks of treatment. Secondary outcomes were changes in the antioxidant status and oxidative stress markers. Although $2-\mathrm{MWT}, \mathrm{MVC}_{\mathrm{Q}}$, and $\mathrm{T}_{\text {lime }}$ were all significantly improved in the supplemented group at the end of the treatment compared to baseline, only $\mathrm{MVC}_{\mathrm{Q}}$ and $\mathrm{T}_{\text {lime }}$ variations were significantly different between groups ( $\mathrm{MVC}_{\mathrm{QD}}: P=0.011 ; \mathrm{MVC}_{\mathrm{QND}}: P=0.004 ; \mathrm{T}_{\text {limeD }}$ : $P=0.028$; $\left.\mathrm{T}_{\text {limQND }}: P=0.011\right)$. Similarly, the vitamin $C(P<0.001)$, vitamin $\mathrm{E}$ as $\alpha$-tocopherol $(P<0.001)$, vitamin $C /$ vitamin $\mathrm{E}$ ratio $(P=0.017)$, vitamin $\mathrm{E} \gamma / \alpha$ ratio $(P=0.022)$ and lipid peroxides $(P<0.001)$ variations were significantly different between groups. In conclusion, vitamin $E$, vitamin $C$, zinc, and selenium supplementation has no significant effect on the 2-MWT, but improves $\mathrm{MVC}_{\mathrm{Q}}$ and $\mathrm{T}_{\text {lime }}$ of both quadriceps by enhancing the antioxidant defenses and reducing oxidative stress. This trial was registered at clinicaltrials.gov (number: NCT01596803).
\end{abstract}

\footnotetext{
Abbreviations: FSHD, facioscapulohumeral dystrophy; Dux4, double homeobox 4 gene; ROS, reactive oxygen species; CuZn-SOD, copper-zinc-dependent superoxide

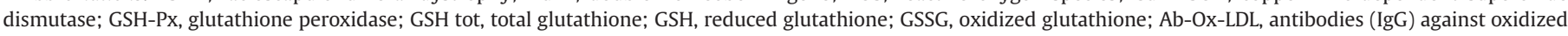

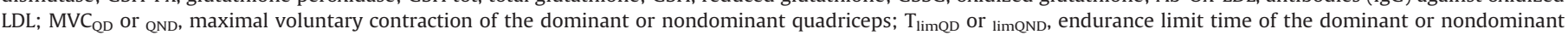
quadriceps; 2-MWT, two minutes walking test

* Correspondence to: INSERM Unit 1046, Hospital Arnaud de Villeneuve, Crastes de Paulet building, 34295 Montpellier, France. Fax: + 33467415231.

E-mail address: dalila.laoudj-chenivesse@inserm.fr (D. Laoudj-Chenivesse).
} 


\section{Introduction}

Facioscapulohumeral muscular dystrophy (FSHD) is the most common inherited skeletal muscle disease of adult life with a prevalence of 4/100,000 in Europe (http://www.orpha.net/orpha com/cahiers/docs/GB/Prevalence_of_rare_diseases_by_alphabetical_ list.pdf). It is characterized by progressive weakness and atrophy of facial, shoulder girdle, and upper arm muscles [1,2]. Magnetic resonance imaging also revealed widespread involvement of leg muscles, particularly of the tibialis anterior and medial gastrocnemius [3]. Approximately $10 \%$ of all patients and $20 \%$ of those older than 50 years will eventually become wheelchair-dependent for outdoor activities. The pattern of muscle weakness is often asymmetrical and the rate and extent of progression may vary considerably with sudden periods of unexplained rapid disease progression $[2,4]$.

FSHD is an autosomal dominant disease and is genetically linked to deletions in chromosome 4q35 [5] within an array of D4Z4 repeats. Each D4Z4 repeat unit includes the open reading frame of double homeobox 4 (DUX4) [6,7], a transcription factor that becomes derepressed in FSHD skeletal muscle cells. DUX4 controls many genes involved in the oxidative stress response and myogenesis, potentially leading to muscle atrophy, differentiation defects, and activation of germline genes [8-12]. Recently, it was shown that mutations in the structural maintenance of the chromosomes flexible hinge domain containing 1 (SMCHD1) gene, which encodes a chromatin modifier of D4Z4, could act as a disease severity modifier in families affected by FSHD $[13,14]$. Despite major progress in the understanding of the genetic basis of FSHD, the exact mechanisms that lead to FSHD defects are not completely understood and no curative treatment is available. However, there is growing evidence that oxidative stress may contribute to FSHD pathology. The hypothesis that oxidative stress responses might be specifically altered in FSHD is supported by the deregulation of enzymes involved in oxidative stress and the consequent increased susceptibility to oxidative agents observed in primary FSHD myoblasts [15-19].

Moreover, we recently reported that reduced physical performance in patients with FSHD is associated with important redox unbalance and oxidative stress in blood [20]. Specifically, patients had higher levels of oxidized DNA and significantly more elevated lipid peroxides levels compared to the control group. The ratio between reduced (GSH) and oxidized glutathione (GSSG) was also strongly decreased in all blood samples from patients with FSHD compared to controls. Although no significant difference was found between FSHD and control blood samples concerning superoxide dismutase (CuZn-SOD) and glutathione peroxidase (GSH-Px) levels, patients had significantly lower levels of zinc (a SOD cofactor), selenium (a GSH-Px cofactor involved in the elimination of lipid peroxides), and vitamin C. Hence, we hypothesized that insufficient intake of antioxidant vitamins and minerals may reduce the body capacity to regulate free radical insults, leading to a condition known as oxidative stress that could affect muscle function performance in patients with FSHD. We thus conducted a pilot randomized double-blind placebo-controlled trial to test whether oral administration of vitamins and minerals could improve the physical performance (2-minute walking test, maximal voluntary contraction, and endurance limit time test of quadriceps of patients with FSHD. Vitamin E (as alpha tocopherol), vitamin C, selenium, and zinc were chosen for this supplementation due to their physiological role in antioxidative processes [21].

\section{Materials and methods}

\section{Study design and patients}

For this randomized double-blind placebo-controlled study, we recruited adults with FSHD at the Clinical Physiology Department,
Montpellier University Hospital (France), between May 2010 and April 2012. Inclusion criteria were between four and nine D4Z4 repeat units and positive family history for FSHD; age between 18 and 60 years; no HIV and/or hepatitis. Exclusion criteria included confinement to a wheelchair, smoking, concomitant comorbidity (cardiac or pulmonary diseases, diabetes, etc.), or being on medication (including mineral or vitamin supplement and /or other antioxidants). The study was approved by the institutional review board and by ANSM (French Health Products Safety Agency). The trial objectives, study design, risks, and benefits were explained and written informed consent was obtained from all participants.

\section{Supplementation}

The supplement choice was based on our previous finding [20] that most patients with FSHD have higher levels of oxidative damage (specifically higher lipid peroxide and oxidized DNA levels), significantly lower GSH/GSSG ratio values (as a consequence of GSSG accumulation), and significantly lower concentrations of vitamin $C$ and essential elements (particularly selenium and zinc) than healthy controls. Vitamin $\mathrm{C}$, the major watersoluble antioxidant, and vitamin E (a lipid-soluble vitamin found in cell membranes and circulating lipoproteins) were selected due to their protective effects against lipid peroxidation in humans [22-24]. Alpha tocopherol is the vitamin E form that is preferentially absorbed and accumulated in humans [25]. Zinc and selenium were selected because lower than normal selenium and zinc levels have been detected in most patients with FSHD and to protect against oxidative stress [20]. The importance of maintaining adequate levels of zinc and selenium is emphasized by studies indicating that low antioxidant status may be associated with increased risk of developing various diseases [26-28]. Selenium was given as selenomethionine because its bioavailability is nearly twice that of selenium as selenite [29]. Zinc gluconate was used because it is absorbed more efficiently [30].

Safe dose ranges were determined based on the recommended dietary allowance (RDA) and the tolerable upper intake levels (UL) for vitamins $\mathrm{E}$ and $\mathrm{C}$ and selenium [31]. The daily dose of zinc gluconate (25 mg zinc gluconate providing $3.5 \mathrm{mg}$ elemental zinc) was based on the internationally recommended daily intake [32] and it is below the RDA recommendations, because it is difficult to determine the level of zinc intake due to the lack of sensitive indicators of zinc nutritional status in humans.

\section{Randomization and masking}

Patients were randomly allocated $(1: 1)$ to receive $500 \mathrm{mg}$ vitamin C, $25 \mathrm{mg}$ zinc gluconate, $200 \mu \mathrm{g}$ selenomethionine, and $400 \mathrm{mg} \mathrm{dl}$-alpha tocopheryl-acetate per day or matching placebo (microcrystalline cellulose). Both were given in encapsulated form (120 capsules per bottle) to ensure that they were indistinguishable and both were provided by CRID PHARMA (France), which was responsible for the quality control of all clinical product batches. All patients were instructed to take one vitamin $C$ capsule at breakfast, one zinc capsule $1 \mathrm{~h}$ after the vitamin $\mathrm{C}$, one selenium capsule $3 \mathrm{~h}$ after the vitamin C (to avoid interactions between antioxidants), and one vitamin E (as alpha tocopherol) capsule after dinner. Pills were taken with food to avoid potential stomach irritation.

Patients' randomization was computer generated with permuted blocks of four and stratified based on the baseline maximal voluntary contraction of the dominant quadriceps $\left(\mathrm{MVC}_{\mathrm{QD}}\right.$ ) ( $>$ or $\leq 5 \mathrm{~kg}$ ). Individual sealed envelopes containing the treatment allocation were given to the trial pharmacist to allow disclosing the treatment group in case of clinical emergency. All personnel 
involved in the study and participants were blind to the treatment until trial completion.

\section{Procedures}

After a screening assessment by telephone interview by the medical team, participants who met the inclusion criteria were enrolled and a first visit was scheduled. Participants were seen four times over 18 weeks: visit 1 (V1: inclusion and clinical characteristics/muscle function); V2 (week 1: levels of oxidative stress markers, randomization, and beginning of treatment); V3 (week 17: muscle performance assessment); and V4 (week 18: end of treatment; levels of oxidative stress markers).

At baseline (V1) and after 16 weeks of supplementation or placebo treatment (V3), functional muscle tests were carried out and clinical features and drug use were recorded. At V2 and V4 venous blood and urine samples were collected between 07:30 and 09:00 after an overnight fast of $12 \mathrm{~h}$ to assess the levels of oxidative stress markers. This week interval between muscle performance testing (at V1 and V3) and blood/urine sample collection (at V2 and V4) was required to avoid potentially confounding effects of exercise-induced oxidative stress on the level of oxidative stress markers. Body-mass index (BMI) was calculated at V1 and V4. Patients began the treatment 1 day after V2 for 17 weeks (V4). At V4, patients returned the bottles and instances of dose violation and the reasons were recorded in the study database.

\section{Study outcomes}

The primary outcomes were changes in the two-minute walking test (2-MWT), maximal voluntary contraction, and endurance limit time of the right and left quadriceps $\left(\mathrm{MVC}_{\mathrm{QR}}, \mathrm{MVC}_{\mathrm{QL}}, \mathrm{T}_{\text {limeR }}\right.$, and $\mathrm{T}_{\text {limel }}$, respectively) compared to baseline, based on our previous finding that physical performance (2-MWT, $\mathrm{MVC}_{\mathrm{Q}}$, and $\mathrm{T}_{\text {lime }}$ ) is related to oxidative stress [20]. The 2-MWT was carried out as previously described [20,33,34]. Patients were asked to walk back and forth around two cones placed in an indoor, straight, $30-\mathrm{m}$ corridor for $2 \mathrm{~min}$. Two tests separated by $20 \mathrm{~min}$ were performed at the maximum walking pace with the goal of covering as much distance as possible. The longest distance covered during the two tests was retained. The $\mathrm{MVC}_{\mathrm{Q}}$ and $\mathrm{T}_{\text {lime }}$ of each quadriceps $\left(\mathrm{MVC}_{\mathrm{QR}}\right.$ and $\mathrm{T}_{\mathrm{limQR}}$ for right quadriceps, $\mathrm{MVC}_{\mathrm{QL}}$ and $\mathrm{T}_{\text {limel }}$ for left quadriceps) were assessed using an adapted exercise bench (Kettler, Germany), as previously reported [20,35]. Patients were in seated position with knees and hips flexed at $90^{\circ} . \mathrm{MVC}_{\mathrm{Q}}$ (in $\mathrm{kg}$ ) was recorded through a strain gauge linked to a computer interface (Biopac, Acknowledge, France). Three to five maximal trials were performed to obtain at least two values with less than $10 \%$ variability. The best value was taken as the $M_{V} C_{Q}$. To assess $\mathrm{T}_{\text {lime }}$ (in minutes: seconds), subjects had to maximally extend each knee against a weight that corresponded to $30 \%$ of the $\mathrm{MVC}_{\mathrm{Q}}$ at a pace of 10 movements per minute, imposed by an audio signal, until exhaustion. The leg with the highest $\mathrm{MVC}_{\mathrm{Q}}$ was considered the dominant leg and was called $\mathrm{MVC}_{\mathrm{QD}}$ and the corresponding endurance was called $\mathrm{T}_{\text {limeD }}$ for the dominant leg, $\mathrm{MVC}_{\mathrm{QND}}$ and $\mathrm{T}_{\text {limend }}$ for the nondominant leg.

Secondary outcomes (assessed at V2 and V4) were changes in the antioxidant status and oxidative stress markers. Vitamin C, vitamin $\mathrm{E}$ (as alpha tocopherol), plasma levels of copper, zinc, and selenium, GSH and GSSG, glutathione peroxidase activity (GSHPx), superoxide dismutase (CuZn-SOD), and markers of lipid peroxidation [lipid peroxides and antibodies (IgG) against oxidized LDL (Ab-Ox-LDL) were measured in venous blood samples. Each parameter was routinely determined at Liege University Hospital, Belgium, as previously described [20]. The detection of urinary
$15-\mathrm{F}_{2 \mathrm{t}}$-isoprostane (a specific marker of lipid peroxidation) was performed by liquid chromatography-mass spectrometry (LC-MS) at Advanced Technology Corporation (ATC, Liège, Belgium); 8-hydroxyguanosine (8-OH-dG, a marker of DNA oxidation) and $15-\mathrm{F}_{2 \mathrm{t}}$-isoprostane levels were normalized to creatinine levels in the urine (8-OHdG ELISA Kit, Japan Institute for the Control of Aging, Fukuroi, Shizuoka) [36].

\section{Statistical analysis}

The sample size was calculated based on the change of 2-MWT values because the distribution of $\mathrm{MVC}_{\mathrm{Q}}$ and $\mathrm{T}_{\text {lime }}$ was not Gaussian. According to our previous study based on a sample of 17 patients with FSHD and using as primary endpoint the 2-MWT values (mean: $117 \mathrm{~m}$, SD: $42 \mathrm{~m}$ ) with an expected difference of $30 \mathrm{~m}$ between groups, the number of subjects required per group was estimated at 25 , with a one-sided alpha risk of $5 \%$ and a power of $80 \%$. As the expected dropout rate was $5 \%$, the final sample size was of 27 patients per group.

The clinical characteristics were described using frequency and proportions for categorical variables. The distribution of continuous variables was assessed (Shapiro-Wilk test). The mean and standard deviation (SD) or the median and interquartile ranges (IQR 25-75\%) were reported for quantitative variables. A linear mixed model for repeated measures was used to examine the effect of supplementation on muscle performance at V3. Time and treatment group and group $\times$ time interactions were modeled as fixed effects with functional measures as dependent variables. The group $\times$ time interaction was tested to evaluate the difference between groups in muscle performance variations at V3 compared to V1. Group and time interactions were also reported separately for each group (within-group variations). The secondary outcomes were analyzed in the same way.

Correlations between variables at baseline and at the end of the study period within each group were fitted by using the Spearman rank sum test, because linearity could not be assumed for all correlations. Values were considered statistically significant at $P<0.05$. Statistical analyses were performed by intention to treat, using SAS version 11 (SAS Institute, Cary, North Carolina). This study was registered at Clinical Trials.gov, number NCT01596803. The name of this trial was Effects of Antioxidant Supplementation on Muscular Function in Patients with Facioscapulohumeral Dystrophy (FSHD).

\section{Results}

Overall, 145 patients with FSHD were screened by phone and 54 met the inclusion criteria and were assessed for eligibility (Fig. 1). One patient was excluded before starting the treatment. The remaining 53 patients were randomly assigned to antioxidant supplementation (supplemented group, $n=26$ ) or placebo (placebo group, $n=27$ ). Patients who completed the study had a medication adherence higher than 95\% (96\% in the supplemented group and $100 \%$ in the placebo group). Side effects were neither observed nor reported throughout the trial.

\section{Baseline characteristics}

\section{Primary outcomes}

Age and sex distributions were similar between groups (Table 1). Conversely, BMI was higher in the supplemented than in the placebo group, but did not change during the study. Moreover, in many patients with FSHD, the anterior tibial and peroneal muscles are often affected before more proximal muscles, leading to steppage gait [37]. This condition was more frequent in the supplemented 


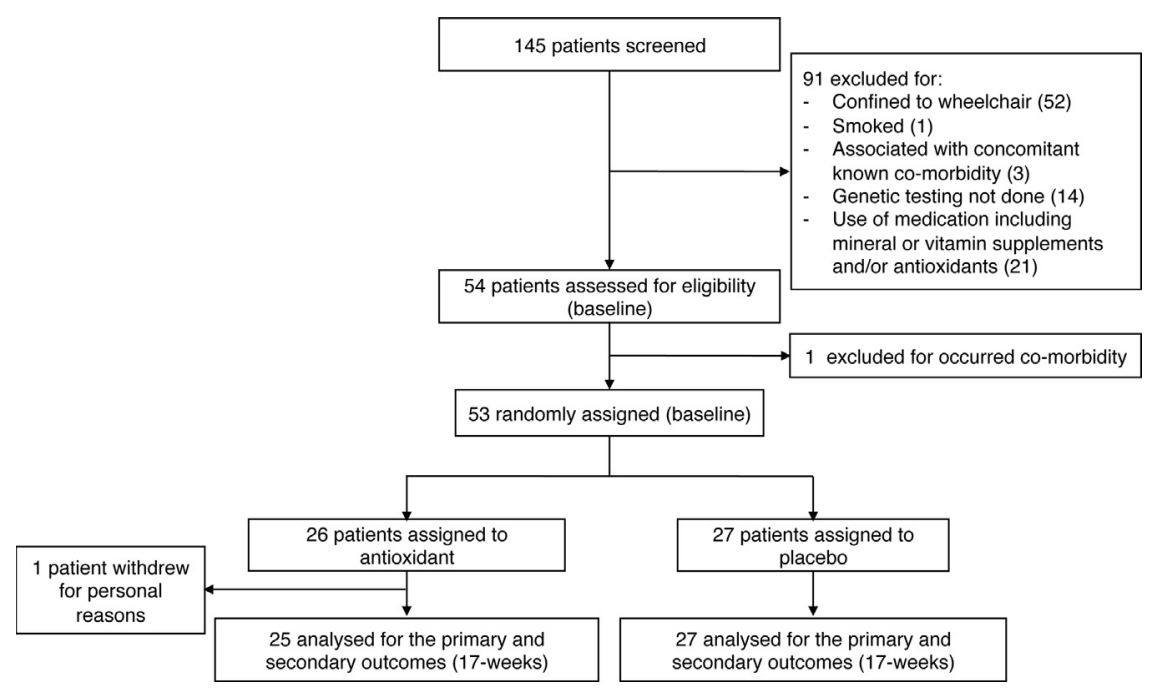

Fig. 1. Enrollment, randomization, and study population.

Table 1

Patients' characteristics at baseline.

\begin{tabular}{lll}
\hline & Supplemented group $(n=26)$ & Placebo group $(n=27)$ \\
\hline $\begin{array}{l}\text { Age }(\mathrm{y}) \\
\text { Sex }\end{array}$ & $42.38 \pm 10.16$ & $37.63 \pm 9.27$ \\
$\quad$ Male & $15(57.69)$ & $13(48.15)$ \\
$\quad$ Female & $11(42.31)$ & $14(51.85)$ \\
Steppage gait & & $6(22.22)$ \\
$\quad$ Yes & $13(50.00)$ & $21(77.78)$ \\
$\quad$ No & $13(50.00)$ & $22.60 \pm 3.47$ \\
BMI $\left(\mathrm{kg} / \mathrm{m}^{2}\right)$ & $24.73 \pm 4.16$ & \\
\hline
\end{tabular}

Data are mean \pm SD or $n(\%)$.

group (50\%: 13/26) than in the placebo group (22\%: 6/27). Some patients could not perform all muscle function tests at V1 and V3 (Table 2). Specifically, maximal voluntary contraction of dominant $\left(\mathrm{MVC}_{\mathrm{QD}}\right)$ and nondominant $\left(\mathrm{MVC}_{\mathrm{QND}}\right)$ quadriceps could be measured in $24 / 25$ patients in the supplemented group, whereas in the placebo group, $\mathrm{MVC}_{\mathrm{QND}}$ was measured in $26 / 27$ patients. The main reason was the inability to maintain isometric contraction for $3 \mathrm{~s}$, resulting in a swing curve that made it impossible to read a correct $\mathrm{MVC}_{\mathrm{Q}}$ value. Only 19/25 patients in the supplemented group and $17 /$ 27 patients of the placebo group performed the dominant quadriceps endurance limit time test $\left(\mathrm{T}_{\text {limeD }}\right)$, while $18 / 25$ and $16 / 27$ patients, respectively, did the nondominant quadriceps endurance limit time test $\left(\mathrm{T}_{\text {limenD }}\right)$. The main reasons were the inability to rise up to $30 \%$ of the $\mathrm{MVC}_{\mathrm{Q}}$ or to maintain the pace of 10 movements per minute.

At baseline (V1) the 2-MWT values were similar between groups (Table 2). Conversely the baseline $M V C_{Q}$ and $T_{\text {lime }}$ values of the dominant and nondominant legs were higher in the supplemented than in the placebo group (Table 2), despite the use of $\mathrm{MVC}_{\mathrm{QD}^{-}}$ based stratified randomization to minimize the FSHD population heterogeneity. One possible explanation of these differences may be that the stratification based on $\mathrm{MVC}_{\mathrm{Q}}$ values $>$ or $\leq 5 \mathrm{~kg}$ was too large. Indeed, the between-group difference in baseline $\mathrm{MVC}_{\mathrm{QD}}$ and $\mathrm{MVC}_{\mathrm{QND}}$ values was maintained when considering only patients with $\mathrm{MVC}_{\mathrm{QD}} \leq 5 \mathrm{~kg}$ [MVC $\mathrm{QDD}_{\mathrm{QD}}$ : median values (IQR) $1.70(0.50)$ for supplemented group $(n=5)$ vs 3.60 (2.00) for placebo group $(n=9)$; $\mathrm{MVC}_{\mathrm{QND}}$ : median values (IQR) $1.40(0.30)$ for the supplemented group ( $n=5)$ vs 2.80 (2.30) for the placebo group $(n=9)$ ] or only patients with $\mathrm{MVC}_{\mathrm{QD}}>5 \mathrm{~kg}$ [MVC $\mathrm{QD}$ : median values (IQR) 16.90 (6.60) for the supplemented group ( $n=19)$ vs 15.20 (14.70) for the placebo group ( $n=18$ ); $\mathrm{MVC}_{\mathrm{QND}}$ : median values (IQR) 14.50 (9.50) for the supplemented group ( $n=19$ ) vs 10.30 (13.60) for the placebo group $(n=17)]$. Similarly, the between-group differences in baseline $\mathrm{T}_{\text {limQD }}$ and $\mathrm{T}_{\text {limQND }}$ values were also maintained when only patients with $\mathrm{MVC}_{\mathrm{QD}}>5 \mathrm{~kg}$ were considered $\left[\mathrm{T}_{\text {limQD }}\right.$ : median values (IQR) 15.03 (12.51) for the supplemented group $(n=18)$ vs 7.50 (5.54) for placebo group $(n=16) ; \mathrm{T}_{\text {limend: }}$ : median values (IQR) 10.30 (11.02) for the supplemented group ( $n=17)$ vs 6.20 (4.27) for the placebo group $(n=15)]$. Only one patient with $\mathrm{MVC}_{\mathrm{QD}} \leq 5 \mathrm{~kg}$ in each subgroup could perform the $\mathrm{T}_{\text {lime }}$ tests.

\section{Secondary outcomes}

At baseline, the mean values of most antioxidant and oxidative stress markers in all study patients were within the reference intervals obtained in a large healthy population [38-40] (Table 3). However, the mean values for the vitamin C/vitamin E ratio and vitamin $\mathrm{E} \gamma / \alpha$ ratio were below the lower limit of the reference intervals and the mean plasma levels of vitamin $C$ and zinc were close to the lower limit of the respective reference intervals. Finally, the mean values of the $\mathrm{Cu} / \mathrm{Zn}$ and GSH/GSSG ratios and the mean plasma levels of lipid peroxides, oxidized DNA, and GSSG were above the upper limit of their reference intervals.

Moreover, higher mean copper (but not zinc) levels and higher mean $\mathrm{Cu} / \mathrm{Zn}$ ratio and lipid peroxide levels (both above the upper limit of the reference ranges) were observed in women than in men, within the supplemented group at baseline (mean \pm SD values; women $(n=11) 1.404 \pm 0.492,1.889 \pm 0.705,1066.18 \pm 587.810$, respectively, vs men $(n=15) 0.813 \pm 0.105,0.996 \pm 0.105,299.47 \pm$ 130.65 , respectively).

\section{After 17 weeks of supplementation}

\section{Primary outcomes}

At V3, the exercise capacity, based on the 2-MWT, was significantly increased only in the supplemented group compared to baseline (Table 4 and Fig. 2). However, no significant betweengroup difference was observed. This difference remained not significant $(P=0.157$; with a power of $23 \%$ ) even when the supplementation effect on the 2-MWT score was assessed only in patients without steppage gait (34/53 patients). Similarly, the $M V C_{Q}$ and $\mathrm{T}_{\text {lime }}$ values of the dominant and nondominant leg at V3 were significantly increased compared to baseline and in this case the between-group difference was significant (Table 4 and Fig. 2).

Similar to baseline, positive and significant correlations were observed between the 2-MWT values and both $\mathrm{MVC}_{\mathrm{QD}}$ and $\mathrm{MVC}_{\mathrm{QND}}$ 


\begin{tabular}{|c|c|c|c|c|c|c|}
\hline & \multicolumn{3}{|c|}{ Supplemented group } & \multicolumn{3}{|c|}{ Placebo group } \\
\hline & $n$ & Mean \pm SD & Median (IQR) & $n$ & Mean \pm SD & Median (IQR) \\
\hline 2-MWT (m) & 25 & $162.44 \pm 61.27$ & $159.00(103.00)$ & 27 & $175.96 \pm 65.51$ & $189.50(91.00)$ \\
\hline $\mathrm{MVC}_{\mathrm{QD}}(\mathrm{kg})$ & 24 & $15.01 \pm 9.99$ & $13.60(15.50)$ & 27 & $14.31 \pm 12.74$ & $10.60(14.00)$ \\
\hline MVC QND (kg) & 24 & $12.55 \pm 9.77$ & $11.70(11.30)$ & 26 & $11.82 \pm 11.68$ & $9.25(10.10)$ \\
\hline Tlim $\mathrm{QD}$ (MM:SS) & 19 & $13: 13 \pm 6: 56$ & $12: 48(14: 07)$ & 17 & $8: 30 \pm 4: 42$ & $8: 20(6: 15)$ \\
\hline Tlim QND (MM:SS) & 18 & $12: 04 \pm 5: 59$ & $10: 10(12: 17)$ & 16 & $6: 54 \pm 4: 17$ & $6: 12(3: 51)$ \\
\hline
\end{tabular}

values and between $\mathrm{MVC}_{\mathrm{QD}}$ and $\mathrm{MVC}_{\mathrm{QND}}$ values at V3 $(P<0.001)$. No significant correlation was found between $\mathrm{T}_{\text {limQD }}$ and $\mathrm{T}_{\text {limeND }}$ or between $\mathrm{T}_{\mathrm{imQ}}$ and $\mathrm{MVC}_{\mathrm{Q}}$ values (Table 5).

Moreover, if only women were considered, no significant difference in the 2-MWT and $\mathrm{MVC}_{\mathrm{Q}}$ (dominant and nondominant leg) values was found in both supplemented and placebo groups between the baseline and the end of treatment $(P=0.366$, $P=0.303, P=0.570$, respectively) (in preparation).

\section{Secondary outcomes}

At the end of the treatment period, between-group differences were found also for some secondary outcome measures (Table 3 ). Plasma vitamin C and vitamin E ( $\alpha$-tocopherol) levels and vitamin E (as $\alpha$-tocopherol) levels normalized to those of the reference lipid cholesterol ( $\alpha$-tocopherol/cholesterol [41] were significantly increased at V4 compared to baseline only in the supplemented group $(P<0.001, P<0.001, P<0.001$, respectively) and the variations of these variables between V2 and V4 differed significantly between groups $(P<0.001, P<0.001, P<0.001$, respectively). The VitC/VitE ratio was significantly reduced compared to baseline only in the supplemented group $(P=0.002)$ and the variation differed significantly between groups $(P=0.017)$. Similarly, the $\gamma /$ $\alpha$-tocopherol ratio, which is a sensitive index of $\alpha$-tocopherol ingestion [42], was significantly reduced compared to baseline in the supplemented group $(P<0.001)$ and its variation was significantly different between groups $(P=0.022)$. While the plasma concentrations of copper and zinc remained unchanged in the supplemented and placebo groups, the copper/zinc $(\mathrm{Cu} / \mathrm{Zn})$ ratio was significantly decreased only in the supplemented group $(P=0.003)$ compared to baseline and the between-group difference was significant $(P=0.031)$. The plasma level of selenium was unchanged in both groups. Whole blood CuZn-SOD and GSH-Px activities were significantly increased in both groups (supplemented group, $P<0.001$ and $P=0.002$, respectively; and placebo group, $P<0.001, P=0.013$, respectively) and the between-group difference was not significant. The GSH /GSSG ratio and GSH levels were decreased significantly in both groups (supplemented group, $P=0.004$ and $P=0.029$, respectively; placebo group, $P=0.017$ and $P=0.027$, respectively); however, the whole blood GSSG level was significantly increased $(P=0.005)$ in comparison to baseline only in the placebo group. No between-group difference for whole blood GSH, GSSG, and GSH/GSSG was observed. The plasma and urinary levels of most oxidative stress markers were significantly reduced only in the supplemented group at the end of treatment in comparison to baseline (Ab-Ox-LDL, $P=0.018$; oxidized DNA, $P=0.038$; urinary $15-\mathrm{F}_{2 \mathrm{t}}$-isoprostane and $15-\mathrm{F}_{2 \mathrm{t}}$-isoprostane/creatinine, $P=0.005$ and $P=0.007$, respectively), but the betweengroup difference was not significant. Finally, the lipid peroxide plasma level was significantly decreased only in the supplemented group $(P<0.001)$ and the between-group difference was significant $(P<0.001)$

Analysis of the correlation between the increase in physical performance variables after antioxidant treatment and the baseline variables (physical performance and antioxidant status and oxidative stress markers) showed that, among the physical performance variables, only the change in $\mathrm{T}_{\text {limeD }}$ in the supplemented group was correlated with the baseline values of physical performance variables. The increase in $\mathrm{T}_{\text {limod }}$ after antioxidant treatment in the supplemented group was significantly and negatively correlated with baseline $\mathrm{T}_{\text {limeD }}(r=-0.547 ; P=0.015)$. Moreover, the increase in 2-MWT after antioxidant treatment was negatively correlated with baseline Ab-Ox-LDL level $(r=-0.460 ; P=0.021)$, while the change in $\mathrm{MVC}_{\mathrm{QD}}$ was negatively correlated with baseline $\mathrm{Cu} / \mathrm{Zn}$ ratio and lipid peroxides $(r=-0.466 ; P=0.022 ; r=-0.484 ; P=0.016$, respectively). No correlation between the change in $M C_{Q N D}$ and oxidative stress markers was found. Finally, the increase in $T_{\text {limend }}$ at the end of treatment was negatively correlated with the baseline VitC/VitE ratio and vitamin $C$ concentration in the supplemented group ( $r=-0.495 ; P=0.043 ; r=-0.662 ; P=0.004$, respectively).

Correlations between variables in all study patients at baseline and in the supplemented group at the end of treatment

Analysis of the correlations between primary and secondary outcome variables in all patients at baseline and in the supplemented group at the end of treatment (Table 5) showed that the significant positive correlation between 2-MWT and GSH level and the negative correlation between $\mathrm{MVC}_{\mathrm{QD}}$ and $\mathrm{Cu} / \mathrm{Zn}$ ratio in all study patients were maintained and even became more robust in the supplemented group at the end of treatment (2-MWT and GSH level correlation: $r=0.311, P=0.026$ at baseline; $r=0.625, P=0.001$ at the end of the study; $\mathrm{MVC}_{\mathrm{QD}}$ and $\mathrm{Cu} / \mathrm{Zn}$ ratio correlation: $r=$ -0.353, $P=0.010$ at baseline, $r=-0.627, P=0.001$; at the end of the study). Also, the positive correlation between $\mathrm{MVC}_{\mathrm{QND}}$ and CuZnSOD activity observed in all patients at baseline was also found in the supplemented group at the end of treatment. The significant positive correlations between $\mathrm{MVC}_{\mathrm{Q}}$ of dominant and nondominant legs and GSH were observed only in the supplemented group at the end of treatment. Moreover, the positive correlation between $\mathrm{T}_{\text {limoND }}$ and urinary $15-\mathrm{F}_{2 \mathrm{t}}$-isoprostane level at baseline (all patients) was found negative at the end of treatment (supplemented group). Finally, no correlation between $\mathrm{T}_{\mathrm{limQD}}$ and antioxidant status or oxidative stress markers could be found both at baseline (all patients) and at the end of treatment (supplemented group).

Analysis of the correlations between oxidative stress markers (Table 5) showed that the negative correlation between GSSG level and GSH/GSSG ratio in all patients was maintained in the supplemented group at the end of treatment. Conversely, the significant positive correlation between GSH level and GSH/GSSG ratio and the significant negative correlation between baseline GSH and GSSG level in all patients were not found in the supplemented group at the end of treatment. Additionally, vitamin E concentration was significantly and negatively correlated with GSSG level and oxidized DNA concentration and positively correlated with the GSH/GSSG ratio only in the supplemented group at the end of the study. The significant negative correlation between vitamin $\mathrm{E}$ 
Table 3

Secondary outcomes.

\begin{tabular}{|c|c|c|c|c|c|c|c|c|c|c|}
\hline & \multirow{2}{*}{$\begin{array}{l}\text { All study patients } \\
(n=52) \\
\text { Baseline }\end{array}$} & \multicolumn{4}{|c|}{ Supplemented group $(n=25)$} & \multicolumn{4}{|c|}{ Placebo group $(n=27)$} & \multirow[b]{2}{*}{$\begin{array}{l}\text { Between group } \\
\text { evolution } \\
\text { (Group } \times \text { Time) } \\
\text { P value }\end{array}$} \\
\hline & & Baseline & Week 17 & $\begin{array}{l}\text { Within-group } \\
\text { variation (Week } \\
\text { 17-Baseline) }\end{array}$ & $\begin{array}{l}\text { Within- } \\
\text { group } \\
\text { evolution } \\
P \text { value }\end{array}$ & Baseline & Week 17 & $\begin{array}{l}\text { Within-group } \\
\text { variation (Week } \\
\text { 17-Baseline) }\end{array}$ & $\begin{array}{l}\text { Within- } \\
\text { group } \\
\text { evolution } \\
\text { P value }\end{array}$ & \\
\hline Vitamin $\mathrm{E} \alpha(\mu \mathrm{g} / \mathrm{mL})$ [8.60-19.24] & $12.14 \pm 3.24$ & $12.19 \pm 3.00$ & $24.76 \pm 6.84$ & $12.40 \pm 5.13$ & $<0.001$ & $12.10 \pm 3.52$ & $11.73 \pm 2.83$ & $-0.31 \pm 2.44$ & 0.667 & $<0.001$ \\
\hline Vitamin E $\gamma(\mu \mathrm{g} / \mathrm{mL})[0.39-2.42]$ & $0.55 \pm 0.31$ & $0.48 \pm 0.26$ & $0.41 \pm 0.19$ & $-0.05 \pm 0.31$ & 0.429 & $0.64 \pm 0.35$ & $0.60 \pm 0.34$ & $-0.03 \pm 0.47$ & 0.579 & 0.855 \\
\hline $\begin{array}{l}\text { Vitamin E } \alpha / \text { cholesterol (mg/g) } \\
4.4-7\end{array}$ & $6.27 \pm 1.14$ & $6.35 \pm 1.22$ & $12.33 \pm 3.24$ & $5.95 \pm 2.78$ & $<0.001$ & $6.19 \pm 1.07$ & $6.19 \pm 1.05$ & $0.01 \pm 0.91$ & 0.997 & $<0.001$ \\
\hline Vitamin C / vitamin E [1-1.1] & $0.82 \pm 0.35$ & $0.81 \pm 0.37$ & $0.60 \pm 0.22$ & $-0.23 \pm 0.32$ & 0.002 & $0.83 \pm 0.34$ & $0.85 \pm 0.40$ & $0.01 \pm 0.35$ & 0.807 & 0.017 \\
\hline Selenium $(\mu \mathrm{g} / \mathrm{L})$ [94-130] & $103.86 \pm 20.84$ & $102.88 \pm 11.74$ & $101.70 \pm 19.10$ & $-1.45 \pm 17.83$ & 0.737 & $104.84 \pm 27.31$ & $98.86 \pm 15.76$ & $-1.77 \pm 18.81$ & 0.328 & 0.654 \\
\hline Lipid peroxide $(\mu \mathrm{mol} / \mathrm{L})[<432]$ & $585.06 \pm 463.90$ & $623.85 \pm 544.97$ & $446.25 \pm 364.76$ & $-134.50 \pm 192.15$ & $<0.001$ & $546.27 \pm 372.68$ & $613.26 \pm 443.38$ & $38.08 \pm 153.17$ & 0.243 & $<0.001$ \\
\hline Oxidized DNA $(\mu \mathrm{g} / \mathrm{L})[0-16]$ & $21.77 \pm 11.62$ & $23.70 \pm 14.23$ & $19.19 \pm 7.65$ & $-4.37 \pm 11.30$ & 0.038 & $19.99 \pm 8.49$ & $17.71 \pm 8.92$ & $-2.02 \pm 8.92$ & 0.285 & 0.432 \\
\hline $\begin{array}{l}\text { Oxidized DNA/creatinine }(\mu \mathrm{g} / \mathrm{g}) \\
{[0-20]}\end{array}$ & $15.97 \pm 7.79$ & $15.37 \pm 8.31$ & $14.71 \pm 5.46$ & $-0.18 \pm 6.33$ & 0.775 & $16.52 \pm 7.40$ & $15.14 \pm 7.24$ & $-1.62 \pm 6.35$ & 0.231 & 0.530 \\
\hline 15- $\mathrm{F}_{2 \mathrm{t}}$-isoprostane $(\mathrm{pg} / \mathrm{mL}) \mathrm{ND}$ & $733.36 \pm 586.16$ & $862.64 \pm 691.95$ & $338.75 \pm 315.25$ & $-520.00 \pm 830.20$ & 0.005 & $604.09 \pm 435.57$ & $329.29 \pm 371.41$ & $-356.92 \pm 641.97$ & 0.168 & 0.305 \\
\hline $\begin{array}{l}\text { 15- } \mathrm{F}_{2 \mathrm{t}^{-}-\text {-isoprostane/creatinine }} \\
\left(10^{-7}\right) \mathrm{ND}\end{array}$ & $5,44 \pm 4.30$ & $5.88 \pm 4.86$ & $2.36 \pm 2.35$ & $-3.42 \pm 5.43$ & 0.007 & $4.99 \pm 3.69$ & $3.00 \pm 3.37$ & $-2.61 \pm 5.12$ & 0.130 & 0.408 \\
\hline Vitamin $E \gamma / \alpha[0.055-0.68]$ & $0,04 \pm 0,02$ & $0,04 \pm 0,02$ & $0,01 \pm 0,006$ & $-0.02 \pm 0.01$ & $<0.001$ & $0.054 \pm 0.028$ & $0.05 \pm 0.02$ & $-0.0023 \pm 0.035$ & 0.599 & 0.022 \\
\hline $\begin{array}{l}\text { Vitamin C }(\mu \mathrm{g} / \mathrm{mL})[F: 8.6-18.8 \\
\text { M:6.21-15.18] }\end{array}$ & $9.22 \pm 3.04$ & $9.16 \pm 3.37$ & $13.88 \pm 3.89$ & $4.46 \pm 4.01$ & $<0.001$ & $9.28 \pm 2.75$ & $9.49 \pm 3.72$ & $0.17 \pm 3.80$ & 0.794 & $<0.001$ \\
\hline $\begin{array}{l}\text { Copper }(\mathrm{mg} / \mathrm{L})[\mathrm{F}: 0.80-1.55 ; \mathrm{M}: \\
0.7-1.4]\end{array}$ & $1.05 \pm 0.37$ & $1.06 \pm 0.43$ & $0.98 \pm 0.37$ & $-0.03 \pm 0.18$ & 0.264 & $1.03 \pm 0.29$ & $1.09 \pm 0.39$ & $0.02 \pm 0.17$ & 0.380 & 0.160 \\
\hline Zinc (mg/L) [0.70-1.20] & $0.79 \pm 0.13$ & $0.79 \pm 0.12$ & $0.83 \pm 0.15$ & $0.04 \pm 0.13$ & 0.152 & $0.80 \pm 0.14$ & $0.79 \pm 0.09$ & $-0.001 \pm 0.16$ & 0.843 & 0.244 \\
\hline Copper/zinc [1-1.17] & $1.35 \pm 0.55$ & $1.37 \pm 0.63$ & $1.19 \pm 0.43$ & $-0.11 \pm 0.18$ & 0.003 & $1.33 \pm 0.47$ & $1.39 \pm 0.52$ & $-0.002 \pm 0.184$ & 0.974 & 0.031 \\
\hline $\mathrm{GSH}$ tot $(\mu \mathrm{mol} / \mathrm{L})[717-1110]$ & $857.88 \pm 177.81$ & $844.19 \pm 185.59$ & $774.21 \pm 149.18$ & $-79.21 \pm 222.20$ & 0.048 & $871.58 \pm 172.22$ & $804.74 \pm 148.35$ & $-67.04 \pm 129.24$ & 0.062 & 0.893 \\
\hline GSH $(\mu \mathrm{mol} / \mathrm{L})[715-1090]$ & $846.98 \pm 181.08$ & $830.34 \pm 192.69$ & $752.69 \pm 144.57$ & $-85.98 \pm 219.35$ & 0.029 & $863.61 \pm 170.83$ & $784.15 \pm 151.61$ & $-80.06 \pm 131.30$ & 0.027 & 0.977 \\
\hline GSSG $(\mu \mathrm{mol} / \mathrm{L})[0.96-10]<4.85$ & $5.44 \pm 9.37$ & $6.91 \pm 9.88$ & $10.75 \pm 12.62$ & $3.39 \pm 10.08$ & 0.121 & $3.97 \pm 8.78$ & $10.27 \pm 13.84$ & $6.49 \pm 12.44$ & 0.005 & 0.384 \\
\hline GSH/GSSG [111-747] & $810.51 \pm 738.22$ & $798.01 \pm 849.04$ & $434.92 \pm 560.62$ & $-349.35 \pm 614.70$ & 0.004 & $823.02 \pm 624.92$ & $532.02 \pm 579.90$ & $-276.39 \pm 559.12$ & 0.017 & 0.662 \\
\hline GSH-Px (UI/g Hb) ND & $46.75 \pm 11.06$ & $45.98 \pm 9.74$ & $57.71 \pm 17.05$ & $11.00 \pm 17.17$ & 0.002 & $47.55 \pm 12.45$ & $56.91 \pm 19.40$ & $8.43 \pm 18.68$ & 0.013 & 0.333 \\
\hline CuZnSOD (UI/g Hb ND & $1835.80 \pm 634.31$ & $1796.65 \pm 604.04$ & $2573.07 \pm 274.69$ & $607.85 \pm 734.08$ & $<0.001$ & $1885.83 \pm 618.36$ & $2542.40 \pm 279.84$ & $712.64 \pm 793.64$ & $<0.001$ & 0.611 \\
\hline Ab-Ox-LDL (UI/L) [200-600] & $482.44 \pm 391.82$ & $483.96 \pm 374.86$ & $329.21 \pm 373.46$ & $-112.63 \pm 282.80$ & 0.018 & $480.92 \pm 415.53$ & $449.85 \pm 397.18$ & $-17.38 \pm 195.39$ & 0.675 & 0.147 \\
\hline
\end{tabular}

Data are mean $\pm \mathrm{SD}$. 
Between-group differences (Week 17-Baseline) of the primary outcome measures.

\begin{tabular}{|c|c|c|c|c|c|c|c|c|c|c|c|}
\hline & \multicolumn{5}{|c|}{ Supplemented group } & \multicolumn{6}{|c|}{ Placebo group } \\
\hline & $n$ & Baseline & Week 17 & $\begin{array}{l}\text { Within-group } \\
\text { variation } \\
\text { (Week 17- } \\
\text { Baseline) }\end{array}$ & $\begin{array}{l}P \text { Within- } \\
\text { supplemented } \\
\text { group } \\
\text { evolution }\end{array}$ & $n$ & Baseline & Week 17 & $\begin{array}{l}\text { Within-group } \\
\text { variation (Week } \\
\text { 17-Baseline) }\end{array}$ & $\begin{array}{l}P \\
\text { Within- } \\
\text { placebo } \\
\text { group } \\
\text { evolution }\end{array}$ & $\begin{array}{l}P \text { value of } \\
\text { between } \\
\text { group } \\
\text { evolution } \\
\text { (Group } \times \\
\text { Time) }\end{array}$ \\
\hline 2-MWT (m) & 25 & $162.44 \pm 61.27$ & $170.80 \pm 61.78$ & $8.36 \pm 14.14$ & $<0.001$ & 27 & $175.96 \pm 65.51$ & $180.23 \pm 68.14$ & $4.27 \pm 8.16$ & 0.064 & 0.208 \\
\hline $\mathrm{MVC}_{\mathrm{QD}}(\mathrm{kg})$ & 24 & $15.01 \pm 9.99$ & $16.16 \pm 10.72$ & $1.15 \pm 1.69$ & $<0.001$ & 27 & $14.31 \pm 12.74$ & $14.33 \pm 13.037$ & $0.02 \pm 1.35$ & 0.939 & 0.011 \\
\hline $\mathrm{MVC}_{\mathrm{QND}}(\mathrm{kg})$ & 24 & $12.55 \pm 9.77$ & $13.85 \pm 9.70$ & $1.30 \pm 2.39$ & 0.002 & 26 & $11.82 \pm 11.68$ & $11.52 \pm 11.93$ & $-0.30 \pm 1.30$ & 0.418 & 0.004 \\
\hline Tlim $_{\mathrm{QD}}$ (MM:SS) & 19 & $13: 13 \pm 6: 56$ & $16: 05 \pm 6: 19$ & $02: 52 \pm 03: 47$ & 0.005 & 17 & $8: 30 \pm 4: 42$ & $8: 12 \pm 5: 03$ & $-00: 18 \pm 04: 28$ & 0.770 & 0.028 \\
\hline Tlim QND (MM:SS) & 18 & $12: 04 \pm 5: 59$ & $14: 51 \pm 5: 41$ & $02: 48 \pm 04: 05$ & 0.001 & 16 & $6: 54 \pm 4: 17$ & $6: 35 \pm 4: 26$ & $-00: 20 \pm 02: 16$ & 0.701 & 0.011 \\
\hline
\end{tabular}

Data are mean \pm SD.

concentration and VitC/VitE ratio and the positive correlation between vitamin $\mathrm{C}$ concentration and VitC/VitE ratio in all patients were maintained in the supplemented group at V4. Moreover, the oxidized DNA level was negatively correlated with GSH level and GSH/GSSG ratio and positively correlated with CuZn-SOD activity in all patients at baseline, but not in the supplemented group at the end of treatment. CuZn-SOD activity was significantly and negatively correlated with GSH, GSH/GSSG, and Ab-Ox-LDL and $15-\mathrm{F}_{2 t^{-}}$ isoprostanes and positively correlated with GSSG in all patients, but not in the supplemented group at the end of treatment. Similarly, the significant positive correlation between baseline $15-\mathrm{F}_{2 \mathrm{t}} \mathrm{t}$-isoprostanes and GSH levels $(P=0.011)$ was not found in the supplemented group at the end of treatment. Conversely, the significant positive correlation between lipid peroxides and $\mathrm{Cu} / \mathrm{Zn}$ ratio in all patients was maintained also in the supplemented group at the end of treatment. Finally, lipid peroxide levels were significantly and positively correlated with GSH-Px activity and vitamin C concentration only in the supplemented group at V4.

\section{Discussion}

The results of this randomized double-blind placebo-controlled trial show that supplementation with vitamin C, vitamin E (as alpha tocopherol), zinc gluconate, and selenomethionine in patients with FSHD significantly improves the maximal voluntary contraction and endurance of both quadriceps by enhancing the antioxidant defenses and reducing oxidative stress.

\section{Effect of supplementation on functional parameters}

At the end of the trial, the 2-MWT score was significantly improved only in the supplemented group compared to baseline, but without significant between-group differences. We chose the 2-MWT as primary outcome and powered our trial in accordance with the predicted changes in 2-MWT based on preliminary findings in 17 homogeneous patients with FSHD. One possible explanation of the absence of significant between-group differences is that the 2-MWT is not appropriate for the heterogeneous population of this study. Indeed, the number of patients with a steppage gait, which increases the risk of falling, was higher in the supplemented than in the placebo group. However, analysis of the effect of supplementation on the 2-MWT score only in the subgroup of patients without steppage gait did not change the result, although we cannot exclude lack of statistical power to detect between-group differences in this smaller subpopulation.

$M V C_{Q}$ and $T_{\text {lime }}$ were also significantly increased only in the supplemented group at the end of the treatment period and in this case the between-group difference was significant. Positive correlations between 2-MWT and both $\mathrm{MVC}_{\mathrm{QD}}$ and $\mathrm{MVC}_{\mathrm{QND}}$ as well as between $\mathrm{MVC}_{\mathrm{QD}}$ and $\mathrm{MVC}_{\mathrm{QND}}$ were observed in all patients at baseline and in the supplemented group at the end of treatment. Conversely, the association between $\mathrm{T}_{\text {limed }}$ and $\mathrm{T}_{\text {limend }}$ values at baseline in all patients was lost in the supplemented group at the end of treatment.

The positive correlation between 2-MWT and GSH level and the negative correlation between $\mathrm{MVC}_{\mathrm{QD}}$ and $\mathrm{Cu} / \mathrm{Zn}$ ratio were more robust in the supplemented group at the end of treatment than in all patients at baseline. In addition, at the end of treatment (but not at baseline) significant positive correlations between the $\mathrm{MVC}_{\mathrm{Q}}$ values of both legs and GSH level were observed in the supplemented group.

Additionally, our data suggest also that the supplementation effect on physical performance variables may differ, depending primarily on the baseline levels of antioxidant status and oxidative stress markers. Indeed, the greatest increase in 2-MWT after antioxidant treatment was associated with the lowest baseline level of $\mathrm{Ab}-\mathrm{Ox}-\mathrm{LDL}$ and the greatest increase in $\mathrm{MVC}_{\mathrm{QD}}$ was associated with the lowest baseline $\mathrm{Cu} / \mathrm{Zn}$ ratio and lipid peroxide levels. Finally, the greatest increase in $\mathrm{T}_{\text {limeD }}$ after antioxidant treatment was correlated with the lowest baseline VitC/VitE ratio and vitamin $\mathrm{C}$ concentration.

\section{Oxidative stress in all patients and placebo group}

Our data show that high levels of oxidative stress markers and low antioxidant concentrations are associated with muscular dysfunction in all patients at baseline, consistent with our previous study [20]. The finding that the mean baseline levels of oxidized DNA and Ab-Ox-LDL in all patients were above the upper limit of the reference ranges suggests that alterations in CuZn-SOD activity may lead to inadequate levels of antioxidant defenses. The analysis of the correlations between oxidative stress makers highlighted a positive correlation between CuZn-SOD activity and oxidized DNA level. This finding, together with the absence of correlation between CuZn-SOD and GSH-Px activities in all patients, raises the possibility that high CuZn-SOD activity, without a concomitant high GSH-Px activity, could exacerbate oxidative stress that may be involved in the FSHD muscle dysfunction. However, it is not known exactly whether high CuZn-SOD activity leads to increase of $\mathrm{H}_{2} \mathrm{O}_{2}$ [43,44] or of other hydroperoxides [45]. SOD is a key antioxidant enzyme due to its antitoxic effect against superoxide anion, but it also transforms $\mathrm{O}_{2}$ into inorganic hydrogen peroxide $\left(\mathrm{H}_{2} \mathrm{O}_{2}\right)$, which will then be reduced by catalase and GSH-Px. Therefore, two toxic species, $\mathrm{O}_{2}^{-}$and $\mathrm{H}_{2} \mathrm{O}_{2}$, are converted into harmless water. The significant negative correlations between 

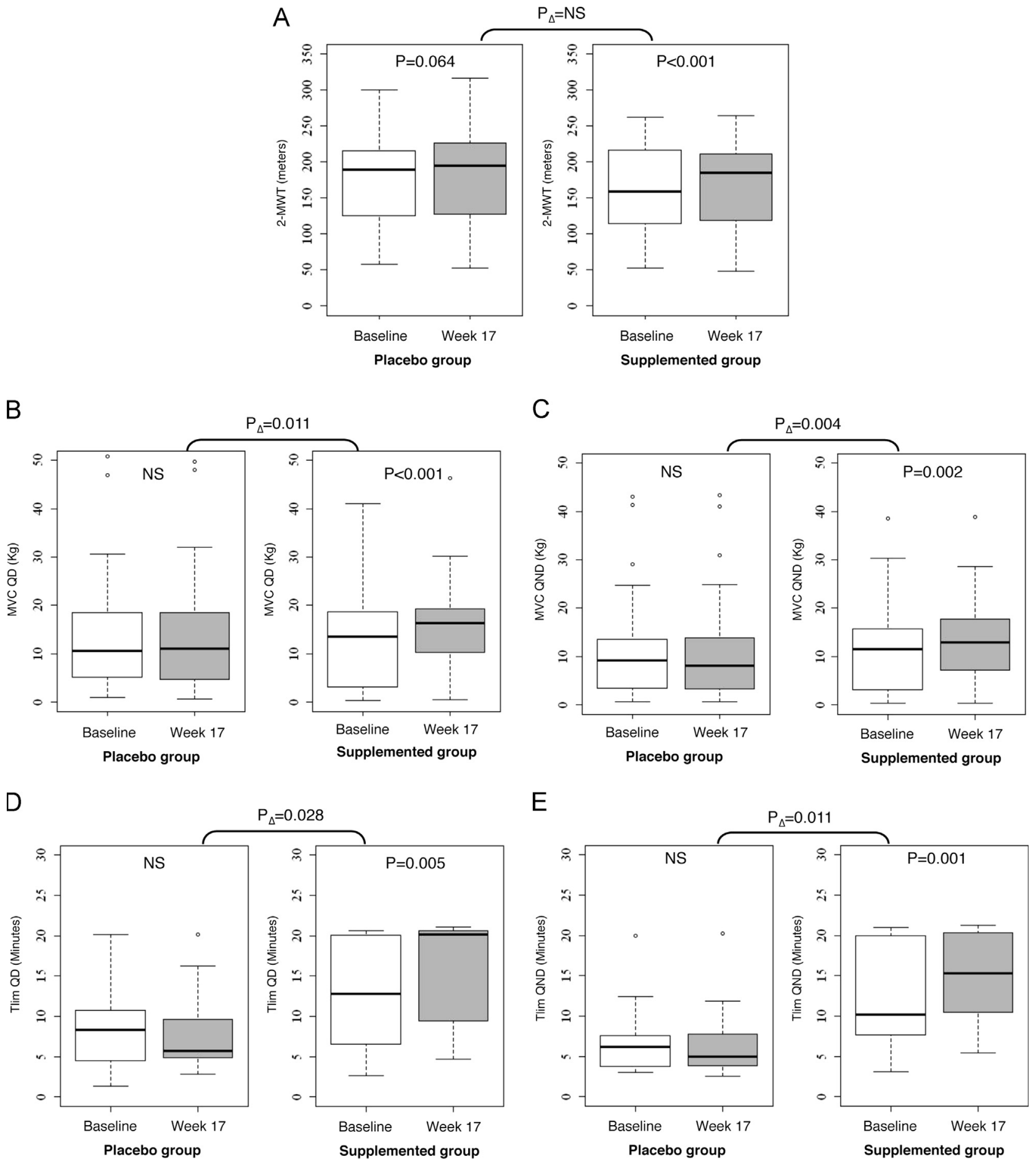

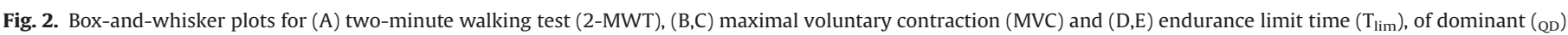

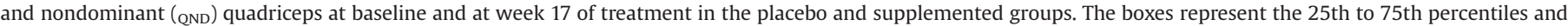

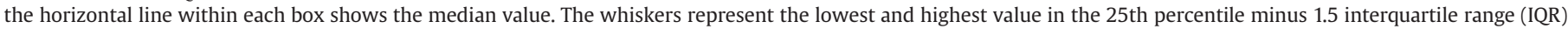

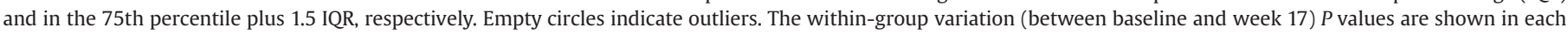
plot and $P_{\Delta}$ (above the plots) indicates the between-group variation (between baseline and week 17) $P$ value. NS, no significant difference.

GSH level and CuZn-SOD activity or oxidized DNA level as well as the significant positive correlations between CuZn-SOD activity and GSSG level and between GSH level and GSH/GSSG ratio in all patients at baseline suggest the protective role of GSH against reactive species [46].

In the placebo group there was a significant increase in CuZnSOD activity that was associated with a significant increase in
GSSG levels and a significant decrease in GSH levels (although still within the reference range) at the end of treatment. Consistent with the GSSG increase, the GSH/GSSG ratio, used as an index of intracellular oxidative stress [47], was reduced. GSH plays a key role in cell resistance to oxidative damage as a free-radical scavenger and protein-bound glutathione and by regeneration of ascorbate or tocopherol in erythrocytes [48]. Increased CuZnSOD 
Table 5

Correlations among antioxidants, oxidative stress markers, and physical performance parameters in all study patients at baseline and in supplemented group at the end of the treatment.

\begin{tabular}{|c|c|c|c|c|}
\hline & \multicolumn{2}{|c|}{$\begin{array}{l}\text { All study patients } \\
\text { at baseline }\end{array}$} & \multicolumn{2}{|c|}{$\begin{array}{l}\text { Supplemented group at } \\
\text { the end of treatment }\end{array}$} \\
\hline & $r$ & $P$ & $r$ & $P$ \\
\hline 2-MWT - MVC $\mathrm{QD}$ & 0.725 & $<0.001$ & 0.793 & $<0.001$ \\
\hline 2-MWT - MVC QND & 0.732 & $<0.001$ & 0.801 & $<0.001$ \\
\hline $\mathrm{MVC}_{\mathrm{QD}}-\mathrm{MVC}_{\mathrm{QND}}$ & 0.935 & $<0.001$ & 0.910 & $<0.001$ \\
\hline $\operatorname{Tlim}_{\mathrm{QD}}-$ Tlim $_{\mathrm{QND}}$ & 0.584 & $<0.001$ & 0.252 & 0.311 \\
\hline 2-MWT - GSH & 0.311 & 0.026 & 0.625 & 0.002 \\
\hline 2-MWT -15- $\mathrm{F}_{2 \mathrm{t}}$-isoprostane & 0.353 & 0.020 & -0.221 & 0.411 \\
\hline $\mathrm{MVC}_{\mathrm{QD}}-$ copper/zinc & -0.353 & 0.010 & -0.627 & 0.001 \\
\hline $\mathrm{MVC}_{\mathrm{QND}}$ - copper/zinc & -0.264 & 0.064 & -0.444 & 0.033 \\
\hline $\mathrm{MVC}_{\mathrm{QD}}-\mathrm{CuZn} \mathrm{SOD}$ & 0.301 & 0.055 & 0.389 & 0.151 \\
\hline $\mathrm{MVC}_{\mathrm{QND}}-\mathrm{CuZn} \mathrm{SOD}$ & 0.311 & 0.050 & 0.225 & 0.420 \\
\hline $\mathrm{MVC}_{\mathrm{QD}}-\mathrm{GSH}$ & 0.122 & 0.387 & 0,463 & 0.026 \\
\hline $\mathrm{MVC}_{\mathrm{QND}}-\mathrm{GSH}$ & 0.185 & 0.210 & 0,549 & 0.006 \\
\hline Tlim ${ }_{\mathrm{QND}}-15-\mathrm{F}_{2 \mathrm{t}}$-isoprostane & 0.425 & 0.022 & -0.609 & 0.047 \\
\hline GSSG - GSH/GSSG & -0.979 & $<0.001$ & -0.977 & $<0.001$ \\
\hline GSH - GSH/GSSG & 0.551 & $<0.001$ & 0.329 & 0.115 \\
\hline GSH - GSSG & -0.405 & 0.003 & -0.213 & 0.316 \\
\hline VitE-GSSG & -0.210 & 0.135 & -0.409 & 0.047 \\
\hline VitE-GSH/GSSG & 0.219 & 0.118 & 0,42 & 0.041 \\
\hline VitE-oxidized DNA & 0.036 & 0.804 & $-0,573$ & 0.034 \\
\hline VitE - VitC/VitE & -0.690 & $<0.001$ & -0.730 & $<0.001$ \\
\hline VitC - VitC/VitE & 0.868 & $<0.001$ & 0.644 & $<0.001$ \\
\hline VitE - VitC & -0.303 & 0.030 & -0.011 & 0.958 \\
\hline Oxidized DNA - GSH & -0.345 & 0.014 & -0.200 & 0.346 \\
\hline Oxidized DNA - CuZnSOD & 0.319 & 0.048 & 0.378 & 0.164 \\
\hline Lipid peroxides-GSH-Px & 0.007 & 0.958 & 0.458 & 0.024 \\
\hline Lipid peroxides-VitC & 0.146 & 0.026 & 0,424 & 0.039 \\
\hline Lipid peroxide - copper/zinc & 0.755 & $<0.001$ & 0.882 & $<0.001$ \\
\hline CuZnSOD - GSH & -0.370 & 0.017 & 0.285 & 0.301 \\
\hline CuZnSOD - GSH/GSSG & -0.518 & $<0.001$ & -0.310 & 0.259 \\
\hline CuZnSOD - Ab-Ox-LDL & -0.444 & 0.004 & 0.107 & 0.703 \\
\hline CuZnSOD - $15-\mathrm{F}_{2 \mathrm{t}}$-isoprostane & -0.341 & 0.045 & 0.329 & 0.296 \\
\hline CuZnSOD - GSSG & 0.498 & $<0.001$ & 0.421 & 0.117 \\
\hline $15-\mathrm{F}_{2 \mathrm{t}}$-isoprostane - GSH & 0.385 & 0.011 & -0.459 & 0.074 \\
\hline
\end{tabular}

Spearman's rank correlation coefficient, $r$. In gray correlations among antioxidants, oxidative stress markers, and physical performance parameters in all patients maintained in supplemented group at the end of treatment.

in erythrocytes may be due to a compensatory adaptive response to oxidative stress. The significant negative correlation between CuZnSOD activity and GSH level implies the free radical scavenger of GSH. However, no change in oxidized DNA levels, which were above the reference range, was observed in the placebo group between baseline and end of treatment. No correlation between vitamin $\mathrm{E}$ and oxidative stress variables was found in all patients at baseline, suggesting that the vitamin $\mathrm{E}$ level, although within the reference range, was not adequate to counteract DNA damage. Moreover, the finding that the vitamin $\mathrm{C}$ mean value in all patients was in the lower limit of the reference range suggests that vitamin $C$ could not have efficiently complemented and potentiated the antioxidant activity of vitamin E [49,50], to ensure maximum protection against oxidative damages. GSH-Px activity in erythrocytes was also increased in the placebo group, possibly as a compensatory adaptive response to oxidative stress. Indeed, the GSH-dependent defense system plays an important role against oxidative damage in cells. As GSH-Px requires GSH as a cofactor to exert its function, the decreased GSH levels could have limited GSH-Px activity [51]. Surprisingly, urinary $15-\mathrm{F}_{2 \mathrm{t}}$-isoprostane, which is produced through free radical-mediated peroxidation of arachidonic acid usually under conditions of increased oxidative stress in animal and human models [52-54], was positively correlated with GSH level in all patients. However, GSH promotes prostaglandin $\mathrm{H}$ synthase (cyclooxygenase)-dependent formation of $\mathrm{F}_{2}$-isoprostanes [55]. In the placebo group, the decrease in 15$\mathrm{F}_{2 \mathrm{t}}$-isoprostane levels at $\mathrm{V} 4$ could be explained by the reduced GSH levels at the end of treatment. Thus, as previously proposed, $15-\mathrm{F}_{2 \mathrm{t}}$-isoprostane level may not be a good biomarker of oxidative stress in some conditions [55].

\section{Effect of supplementation on oxidative stress markers}

Our data suggest that vitamin C, vitamin E (as alpha tocopherol), selenium, and zinc supplementation for 17 weeks may contribute to minimize the adverse effects of oxidative damage (particularly in lipid peroxides) and free radical generation and promote GSH antioxidant activity. Therefore, the modulation of GSH-Px and CuZn-SOD activities on supplementation might reflect the decrease in oxidative stress.

A significant decrease in oxidized DNA and Ab-Ox-LDL levels was observed between baseline and end of treatment only in the supplemented group, but the between-group difference was not significant. Moreover, after 17 weeks of treatment, blood lipid peroxides were decreased only in the supplemented group and the between-groups difference was significant. The method we used to quantify lipid peroxidation measures various aldehydes from lipid hydroperoxides. Unlike reactive free radicals, aldehydes are rather long-lived and can, therefore, diffuse and reach distant targets. The significant decrease in the $\mathrm{Cu} / \mathrm{Zn}$ ratio suggests an effect of zinc administration, although zinc concentration was relatively unchanged at the end of the treatment compared to baseline. Blood zinc levels do not necessarily reflect the intracellular zinc status due to tight homeostatic control mechanisms [56]. The decrease in the $\mathrm{Cu} / \mathrm{Zn}$ ratio suggests the protective effect of zinc administration on the cooper-induced lipid peroxides [57]. However, the significant positive correlation between $\mathrm{Cu} / \mathrm{Zn}$ ratio and lipid peroxides in all patients at baseline was maintained also at the end of treatment in the supplemented group. This may be explained by the fact that higher mean copper (but not zinc) levels and significant higher mean $\mathrm{Cu} / \mathrm{Zn}$ ratios and lipid peroxide levels (both above the upper limit of the reference ranges) were observed in women $(n=11)$ than in men $(n=15)$, within the supplemented group at baseline. Moreover, if only women were considered, no significant difference in the 2-MWT and $\mathrm{MVC}_{\mathrm{Q}}$ (dominant and nondominant leg) values was found in both supplemented and placebo groups between the baseline and the end of treatment, suggesting that in women with high levels of copper and high $\mathrm{Cu} / \mathrm{Zn}$ ratio, supplementation does not have any significant effect on 2-MWT and $\mathrm{MVC}_{\mathrm{Q}}$ (in preparation). Together, our data suggest that the $\mathrm{Cu} / \mathrm{Zn}$ ratio and copper level are more important than the level of zinc alone. The positive correlation between vitamin $C$ and lipid peroxides at the end of treatment could be related to the prooxidant effect of vitamin $\mathrm{C}$ [58]. The higher GSH-Px activity in the supplemented group compared to controls suggests that the selenium concentration was sufficient to allow for the increase in GSH-Px activity [59]. Moreover, the lack of changes in selenium blood level (a marker of short-term changes in selenium concentration) and the increased blood GSH-Px activity between the baseline and the end of treatment in the supplemented group may reflect a mobilization of selenium into organs [60]. The significant positive correlation between GSH-Px activity and lipid peroxides in the supplemented group at the end of the treatment, but not in all patients at baseline, could suggest an adaptive response to the increased production of lipid peroxides. Moreover, the vitamin E concentration was significantly and negatively correlated with GSSG level and oxidized DNA concentration and also positively correlated with GSH/GSSG ratio in the supplemented group at the end of the treatment, possibly indicating a strong antioxidant effect of vitamin E. However, such correlations were not observed for vitamin C, suggesting that optimal antioxidant protection requires synchronously optimized 
vitamin $\mathrm{C}$ and $\mathrm{E}$ dosage. Finally, urinary $15-\mathrm{F}_{2 \mathrm{t}}$-isoprostane levels were significantly reduced in the supplemented group at the end of treatment in comparison to baseline, suggesting the protective effect of the supplementation against lipid peroxidation.

The rationale for this study was based on growing evidence pointing to a crucial role of free radical-mediated injury in the pathogenesis of patients with FSHD [18-20,61-64]. Our data show that oxidative stress and inadequate levels of antioxidant markers may be associated with muscular dysfunction, consistent with our previous study [20]. Moreover, they suggest that the imbalance between free radical generation and scavenging could exacerbate oxidative stress in FSHD. It is known that low GSH-Px activity can increase the susceptibility to lipid peroxidation damage $[65,66]$. GSH-Px plays a key role in modulating the GSH/GSSG ratio and indirectly affects the cell NADP/NADPH ratio [67]. CuZn-SOD is a key enzyme in the dismutation of superoxide radicals generated by the cell oxidative metabolism and, consequently, it has a key antioxidant role. Copper and zinc participate in SOD enzymatic activity to protect against free radicals and, therefore, have an important adjunct role in oxidative balance [68].

Several genes involved in susceptibility to oxidative stress are affected by DUX4 derepression $[8,12]$ and the acute cell toxicity mediated by DUX4 overexpression in mouse C2C12 myoblasts is alleviated by the addition of antioxidants, such as ascorbic acid and vitamin E, to the culture medium [8]. Similarly, Bosnakovski et al. [64] reported that $60 \%$ of the inhibitors of DUX4 toxicity in C2C12 myoblasts they identified by high-throughput screening also protect against oxidative stress. Many studies have suggested that excessive generation of reactive oxygen species contributes to muscle damage and degeneration of dystrophic muscle [69-73]. Among the many targets of ROS, those involved in muscle contractile function and membrane stability are of special interest for muscular dystrophy. Numerous studies reported the efficient protection provided by antioxidants against muscle damage in pathological states characterized by an increase in oxidative stress [74-82]. Further studies are required to confirm the beneficial effect of this antioxidant supplementation in larger groups of patients with FSHD and to determine the precise mechanisms and targets involved in this effect. The long-term effects of this antioxidant supplementation also need to be investigated. Moreover, the dosage of these vitamins and minerals must be optimized to achieve the maximal benefit.

In conclusion, the results of this randomized, double-blind, placebo-controlled pilot clinical trial show that vitamin C, vitamin E (as alpha tocopherol), selenium, and zinc supplementation may improve skeletal muscle function in patients with FSHD. They also suggest that an antioxidant strategy adapted to the FSHD-specific "oxidative stress" may be a relevant therapeutic approach for these patients.

\section{Acknowledgments}

This study was supported by Stichting FSHD (The Netherlands), Amis FSH Europe (France), and Montpellier University Hospital (AOI). We are grateful to the patients from the Amis FSH Europe Association. We thank E. Andermarcher for critical reading of the manuscript. The study is dedicated to the memory of Miss Patricia Salustri. The authors have declared that no conflict of interest exists.

\section{References}

[1] Pandya, S.; King, W. M.; Tawil, R. Facioscapulohumeral dystrophy. Phys. Ther 88:105-113; 2008

[2] Tawil, R.; Van Der Maarel, S. M. Facioscapulohumeral muscular dystrophy. Muscle Nerve 34:1-15; 2006.
[3] Olsen, D. B.; Gideon, P.; Jeppesen, T. D.; Vissing, J. Leg muscle involvement in facioscapulohumeral muscular dystrophy assessed by MRI. J. Neurol. 253: 1437-1441; 2006.

[4] Richards, M.; Coppee, F.; Thomas, N.; Belayew, A.; Upadhyaya, M. Facioscapulohumeral muscular dystrophy (FSHD): an enigma unravelled? Hum. Genet. 131:325-340; 2012.

[5] van Deutekom, J. C.; Wijmenga, C.; van Tienhoven, E. A.; Gruter, A. M.; Hewitt, J. E.; Padberg, G. W.; van Ommen, G. J.; Hofker, M. H.; Frants, R. R. FSHD associated DNA rearrangements are due to deletions of integral copies of a $3.2 \mathrm{~kb}$ tandemly repeated unit. Hum. Mol. Genet 2:2037-2042; 1993.

[6] Gabriels, J.; Beckers, M. C.; Ding, H.; De Vriese, A.; Plaisance, S.; van der Maarel, S. M.; Padberg, G. W.; Frants, R. R.; Hewitt, J. E.; Collen, D.; Belayew, A. Nucleotide sequence of the partially deleted D4Z4 locus in a patient with FSHD identifies a putative gene within each $3.3 \mathrm{~kb}$ element. Gene 236:25-32; 1999.

[7] Hewitt, J. E.; Lyle, R.; Clark, L. N.; Valleley, E. M.; Wright, T. J.; Wijmenga, C.; van Deutekom, J. C.; Francis, F.; Sharpe, P. T.; Hofker, M.; et al. Analysis of the tandem repeat locus D4Z4 associated with facioscapulohumeral muscular dystrophy. Hum. Mol. Genet 3:1287-1295; 1994.

[8] Bosnakovski, D.; Xu, Z.; Gang, E. J.; Galindo, C. L.; Liu, M.; Simsek, T.; Garner, H. R.; Agha-Mohammadi, S.; Tassin, A.; Coppee, F.; Belayew, A.; Perlingeiro, R. R. Kyba, M. An isogenetic myoblast expression screen identifies DUX4-mediated FSHD-associated molecular pathologies. EMBO J. 27:2766-2779; 2008.

[9] Wallace, L. M.; Garwick, S. E.; Mei, W.; Belayew, A.; Coppee, F.; Ladner, K. J.; Guttridge, D.; Yang, J.; Harper, S. Q. DUX4, a candidate gene for facioscapulohumeral muscular dystrophy, causes p53-dependent myopathy in vivo. Ann Neurol. ; 2010.

[10] Vanderplanck, C.; Ansseau, E.; Charron, S.; Stricwant, N.; Tassin, A.; LaoudjChenivesse, D.; Wilton, S. D.; Coppee, F.; Belayew, A. The FSHD atrophic myotube phenotype is caused by DUX4 expression. PLoS One 6:e26820; 2011.

[11] Sharma, V.; Harafuji, N.; Belayew, A.; Chen, Y. W. DUX4 differentially regulates transcriptomes of human rhabdomyosarcoma and mouse C2C12 cells. PLoS One 8:e64691; 2013.

[12] Geng, L. N.; Yao, Z.; Snider, L.; Fong, A. P.; Cech, J. N.; Young, J. M.; van der Maarel, S. M.: Ruzzo, W. L.; Gentleman, R. C.: Tawil, R.; Tapscott, S. J. DUX4 activates germline genes, retroelements, and immune mediators: implications for facioscapulohumeral dystrophy. Dev Cell 22:38-51; 2012.

[13] Lemmers, R. J.; van der Vliet, P. J.; Klooster, R.; Sacconi, S.; Camano, P.; Dauwerse, J. G.; Snider, L.; Straasheijm, K. R.; van Ommen, G. J.; Padberg, G. W.; Miller, D. G.; Tapscott, S. J.; Tawil, R.; Frants, R. R.; van der Maarel, S. M. A unifying genetic model for facioscapulohumeral muscular dystrophy. Science 329:1650-1653: 2010.

[14] Sacconi, S.; Lemmers, R. J.; Balog, J.; van der Vliet, P. J.; Lahaut, P.; van Nieuwenhuizen, M. P.; Straasheijm, K. R.; Debipersad, R. D.; Vos-Versteeg, M.; Salviati, L.; Casarin, A.; Pegoraro, E.; Tawil, R.; Bakker, E.; Tapscott, S. J.; Desnuelle, C.; van der Maarel, S. M. The FSHD2 gene SMCHD1 is a modifier of disease severity in families affected by FSHD1. Am. J. Hum. Genet. ; 2013.

[15] Winokur, S. T.; Chen, Y. W.; Masny, P. S.; Martin, J. H.; Ehmsen, J. T.; Tapscott, S. J.; van der Maarel, S. M.; Hayashi, Y.; Flanigan, K. M. Expression profiling of FSHD muscle supports a defect in specific stages of myogenic differentiation. Hum. Mol. Genet 12:2895-2907; 2003.

[16] Osborne, R. J.; Welle, S.; Venance, S. L.; Thornton, C. A.; Tawil, R. Expression profile of FSHD supports a link between retinal vasculopathy and muscular dystrophy. Neurology 68:569-577; 2007.

[17] Cheli, S.; Francois, S.; Bodega, B.; Ferrari, F.; Tenedini, E.; Roncaglia, E.; Ferrari, S.; Ginelli, E.; Meneveri, R. Expression profiling of FSHD-1 and FSHD-2 cells during myogenic differentiation evidences common and distinctive gene dysregulation patterns. PLoS One 6:e20966; 2011.

[18] Winokur, S. T.; Barrett, K.; Martin, J. H.; Forrester, J. R.; Simon, M.; Tawil, R. Chung, S. A.; Masny, P. S.; Figlewicz, D. A. Facioscapulohumeral muscular dystrophy (FSHD) myoblasts demonstrate increased susceptibility to oxidative stress. Neuromuscul. Disord 13:322-333; 2003.

[19] Barro, M.: Carnac, G.; Flavier, S. Mercier, J.: Vassetzky, Y. Laoudj-Chenivesse, D. Myoblasts from affected and non-affected FSHD muscles exhibit morphological differentiation defects. J. Cell. Mol. Med. 14:275-289; 2010.

[20] Turki, A.; Hayot, M.; Carnac, G.; Pillard, F.; Passerieux, E.; Bommart, S.; Raynaud de Mauverger, E.; Hugon, G.; Pincemail, J.; Pietri, S.; Lambert, K.; Belayew, A.; Vassetzky, Y.; Juntas Morales, R.; Mercier, J.; Laoudj-Chenivesse, D. Functional muscle impairment in facioscapulohumeral muscular dystrophy is correlated with oxidative stress and mitochondrial dysfunction. Free Radic. Biol. Med. 53:1068-1079; 2012

[21] Fang, Y. Z.; Yang, S.; Wu, G. Free radicals, antioxidants, and nutrition. Nutrition 18:872-879; 2002

[22] Hillstrom, R. J.; Yacapin-Ammons, A. K.; Lynch, S. M. Vitamin C inhibits lipid oxidation in human HDL. J. Nutr. 133:3047-3051; 2003.

[23] Awad, J. A.; Morrow, J. D.; Hill, K. E.; Roberts 2nd L. J.; Burk, R. F. Detection and localization of lipid peroxidation in selenium- and vitamin E-deficient rats using F2-isoprostanes. J. Nutr. 124:810-816; 1994.

[24] Niki, E. Antioxidants in relation to lipid peroxidation. Chem. Phys. Lipids 44:227-253; 1987

[25] Rigotti, A. Absorption, transport, and tissue delivery of vitamin E. Mol. Aspects Med. 28:423-436; 2007.

[26] Prasad, A. S.; Fitzgerald, J. T.; Hess, J. W.; Kaplan, J.; Pelen, F.; Dardenne, M. Zinc deficiency in elderly patients. Nutrition 9:218-224: 1993.

[27] Hansson, L. E.; Nyren, O.; Bergstrom, R.; Wolk, A.; Lindgren, A.; Baron, J.; Adami, H. O. Nutrients and gastric cancer risk. A population-based casecontrol study in Sweden. Int. J. Cancer 57:638-644; 1994. 
[28] Mark, S. D.; Qiao, Y. L.; Dawsey, S. M.; Wu, Y. P.; Katki, H.; Gunter, E. W.; Fraumeni Jr J. F.; Blot, W. J.; Dong, Z. W.; Taylor, P. R. Prospective study of serum selenium levels and incident esophageal and gastric cancers. J. Natl. Cancer Inst. 92:1753-1763; 2000.

[29] Xia, Y.; Hill, K. E.; Byrne, D. W.; Xu, J.; Burk, R. F. Effectiveness of selenium supplements in a low-selenium area of China. Am. J. Clin. Nutr. 81:829-834; 2005.

[30] Brown, K. H.; Rivera, J. A.; Bhutta, Z.; Gibson, R. S.; King, J. C.; Lonnerdal, B.; Ruel, M. T.; Sandtrom, B.; Wasantwisut, E.; Hotz, C., International Zinc Nutrition Consultative Group (IZiNCG) technical document \#1. Assessment of the risk of zinc deficiency in populations and options for its control. Food Nutr. Bull 25:S99-203; 2004.

[31] Monsen, E. R. Dietary reference intakes for the antioxidant nutrients: vitamin C, vitamin E, selenium, and carotenoids. J. Am. Diet. Assoc. 100:637-640; 2000.

[32] Trumbo, P.; Yates, A. A.; Schlicker, S.; Poos, M. Dietary reference intakes: vitamin $\mathrm{A}$, vitamin $\mathrm{K}$, arsenic, boron, chromium, copper, iodine, iron, manganese, molybdenum, nickel, silicon, vanadium, and zinc. J. Am. Diet. Assoc. 101:294-301; 2001.

[33] Brooks, D.; Parsons, J.; Hunter, J. P.; Devlin, M.; Walker, J. The 2-minute walk test as a measure of functional improvement in persons with lower limb amputation. Arch. Phys. Med. Rehabil. 82:1478-1483; 2001.

[34] Leung, A. S.; Chan, K. K.; Sykes, K.; Chan, K. S. Reliability, validity, and responsiveness of a 2-min walk test to assess exercise capacity of COPD patients. Chest 130:119-125; 2006

[35] Koechlin, C.; Couillard, A.; Simar, D.; Cristol, J. P.; Bellet, H.; Hayot, M.; Prefaut, C. Does oxidative stress alter quadriceps endurance in chronic obstructive pulmonary disease? Am. J. Respir. Crit Care Med. 169:1022-1027; 2004.

[36] Shimoi, K.; Kasai, H.; Yokota, N.; Toyokuni, S.; Kinae, N. Comparison between high-performance liquid chromatography and enzyme-linked immunosorbent assay for the determination of 8-hydroxy-2'-deoxyguanosine in human urine. Cancer Epidemiol. Biomarkers Prev 11:767-770; 2002.

[37] Lunt, P. W.; Harper, P. S. Genetic counselling in facioscapulohumeral muscular dystrophy. J. Med. Genet. 28:655-664; 1991.

[38] Haleng, J.; Pincemail, J.; Defraigne, J. O.; Charlier, C.; Chapelle, J. P. [Oxidative stress]. Rev. Med. Liege 62:628-638; 2007.

[39] Pincemail, J.; Le Goff, C.; Charlier, C.; Gillion, P.; Cheramy-Bien, J. P.; Van Honacker, E.; Chapelle, J. P.; Defraigne, J. O. Evaluation biologique du stress oxydant: application en routine clinique. Nutr. Endocrinol :16-31; 2009.

[40] Pincemail, J.; Vanbelle, S.; Gaspard, U.; Collette, G.; Haleng, J.; Cheramy-Bien, J. P.; Charlier, C.; Chapelle, J. P.; Giet, D.; Albert, A.; Limet, R.; Defraigne, J. O. Effect of different contraceptive methods on the oxidative stress status in women aged 4048 years from the ELAN study in the province of Liege, Belgium. Hum. Reprod. 22:2335-2343; 2007.

[41] Thurnham, D. I.; Davies, J. A.; Crump, B. J.; Situnayake, R. D.; Davis, M. The use of different lipids to express serum tocopherol: lipid ratios for the measurement of vitamin E status. Ann. Clin. Biochem. 23(Pt 5):514-520; 1986.

[42] Baker, H.; Handelman, G. J.; Short, S.; Machlin, L. J.; Bhagavan, H. N.; Dratz, E. A. Frank, O. Comparison of plasma alpha and gamma tocopherol levels following chronic oral administration of either all-rac-alpha-tocopheryl acetate or RRR-alpha-tocopheryl acetate in normal adult male subjects. Am. J. Clin. Nutr. 43:382-387; 1986.

[43] Halliwell, B. Reactive oxygen species and the central nervous system. J. Neurochem. 59:1609-1623; 1992.

[44] Yim, M. B.; Chock, P. B.; Stadtman, E. R. Enzyme function of copper, zinc superoxide dismutase as a free radical generator. J. Biol. Chem. 268:4099-4105: 1993.

[45] Omar, B. A.; McCord, J. M. The cardioprotective effect of Mn-superoxide dismutase is lost at high doses in the postischemic isolated rabbit heart. Free Radic. Biol. Med. 9:473-478; 1990.

[46] Lushchak, V. I. Glutathione homeostasis and functions: potential targets for medical interventions. J. Amino Acids 2012:736837; 2012.

[47] Nemeth, I.; Boda, D. The ratio of oxidized/reduced glutathione as an index of oxidative stress in various experimental models of shock syndrome. Biomed. Biochim. Acta 48:S53-57; 1989.

[48] Wohaieb, S. A.; Godin, D. V. Alterations in free radical tissue-defense mechanisms in streptozocin-induced diabetes in rat. Effects of insulin treatment. Diabetes 36:1014-1018; 1987.

[49] Niki, E.; Kawakami, A.; Yamamoto, Y.; Kamiya, Y. Synergistic inhibition of oxidation of phosphatidycholine liposomes in aqueous dispersion by vitamin E and vitamin C. Bull. Chem. Soc. Jpn. 58:1971-1975; 1985.

[50] Niki, E.; Tsuchiya, Y.; Tanimura, R.; Kamiya, Y. Regeneration of vitamin E from $\alpha$-chromanoxy radical by glutathione and vitamin C. Chem. Lett. :789-792; 1982.

[51] Li, S.; Yan, T.; Yang, J. Q.; Oberley, T. D.; Oberley, L. W. The role of cellular glutathione peroxidase redox regulation in the suppression of tumor cell growth by manganese superoxide dismutase. Cancer Res. 60:3927-3939; 2000.

[52] Morrow, J. D.; Chen, Y.; Brame, C. J.; Yang, J.; Sanchez, S. C.; Xu, J.; Zackert, W. E.; Awad, J. A.; Roberts, L. J. The isoprostanes: unique prostaglandin-like products of free-radical-initiated lipid peroxidation. Drug Metab. Rev. 31: 117-139; 1999.

[53] Morrow, J. D.; Frei, B.; Longmire, A. W.; Gaziano, J. M.; Lynch, S. M.; Shyr, Y.; Strauss, W. E. Oates, J. A.; Roberts 2nd L. J. Increase in circulating products of lipid peroxidation (F2-isoprostanes) in smokers. Smoking as a cause of oxidative damage. N. Engl. J. Med. 332:1198-1203; 1995.
[54] Barden, A.; Beilin, L. J.; Ritchie, J.; Croft, K. D.; Walters, B. N.; Michael, C. A. Plasma and urinary 8-iso-prostane as an indicator of lipid peroxidation in preeclampsia and normal pregnancy. Clin. Sci. (Lond.) 91:711-718; 1996.

[55] Tsikas, D.; Suchy, M. T.; Niemann, J.; Tossios, P.; Schneider, Y.; Rothmann, S.; Gutzki, F. M.; Frolich, J. C.; Stichtenoth, D. O. Glutathione promotes prostaglandin $\mathrm{H}$ synthase (cyclooxygenase)-dependent formation of malondialdehyde and 15(S)-8-iso-prostaglandin F2alpha. FEBS Lett. 586:3723-3730; 2012.

[56] Wood, R. J. Assessment of marginal zinc status in humans. J. Nutr. 130: 1350S-1354S; 2000

[57] Filipe, P. M.; Fernandes, A. C.; Manso, C. F. Effects of zinc on copper-induced and spontaneous lipid peroxidation. Biol. Trace Elem. Res. 47:51-56; 1995.

[58] Carr, A.; Frei, B. Does vitamin C act as a pro-oxidant under physiological conditions? FASEB J 13:1007-1024; 1999.

[59] Sunde, R. A. Selenium. In: Bowman, B. A., Russel, R. M., editors. Present knowledge in nutrition. Washington: ILSI Press, Washington, DC; 2006 p. 480-497.

[60] Hatfield, D. L.; Berry, M. J.; Gladyshev, V. N. Selenium. Its molecular biology and role in human health. 2nd ed.. New York: Springer; 2006.

[61] Celegato, B.; Capitanio, D.; Pescatori, M.; Romualdi, C.; Pacchioni, B.; Cagnin, S. Vigano, A.; Colantoni, L.; Begum, S.; Ricci, E.; Wait, R.; Lanfranchi, G.; Gelfi, C. Parallel protein and transcript profiles of FSHD patient muscles correlate to the D4Z4 arrangement and reveal a common impairment of slow to fast fibre differentiation and a general deregulation of MyoD-dependent genes. Proteomics 6:5303-5321; 2006.

[62] Laoudj-Chenivesse, D.; Carnac, G.; Bisbal, C.; Hugon, G.; Bouillot, S.; Desnuelle C.; Vassetzky, Y.; Fernandez, A. Increased levels of adenine nucleotide translocator 1 protein and response to oxidative stress are early events in facioscapulohumeral muscular dystrophy muscle. J. Mol. Med. 83:216-224; 2005.

[63] Macaione, V.; Aguennouz, M.; Rodolico, C.; Mazzeo, A.; Patti, A.; Cannistraci, E.; Colantone, L.; Di Giorgio, R. M.; De Luca, G.; Vita, G. RAGE-NF-kappaB pathway activation in response to oxidative stress in facioscapulohumeral muscular dystrophy. Acta Neurol. Scand. 115:115-121; 2007.

[64] Bosnakovski, D.; Choi, S. H.; Strasser, J. M.; Toso, E. A.; Walters, M. A.; Kyba, M. High-throughput screening identifies inhibitors of DUX4-induced myoblast toxicity. Skelet. Muscle 4:4; 2014.

[65] Netelson, S. Microtechniques of clinical chemistry for the routine laboratory. Illinois: Springfield; 1957; 381;

[66] Raes, M.; Michiels, C.; Remacle, J. Comparative study of the enzymatic defense systems against oxygen-derived free radicals: the key role of glutathione peroxidase. Free Radic. Biol. Med. 3:3-7; 1987.

[67] DiSilvestro, R. A.; Selsby, J.; Siefker, K. A pilot study of copper supplementation effects on plasma F2alpha isoprostanes and urinary collagen crosslinks in young adult women. J. Trace Elem. Med. Biol. 24:165-168; 2010.

[68] Ozcelik, D.; Ozaras, R.; Gurel, Z.; Uzun, H.; Aydin, S. Copper-mediated oxidative stress in rat liver. Biol. Trace Elem. Res. 96:209-215; 2003.

[69] Ragusa, R. J.; Chow, C. K.; Porter, J. D. Oxidative stress as a potential pathogenic mechanism in an animal model of Duchenne muscular dystrophy. Neuromuscul. Disord 7:379-386; 1997.

[70] Rodriguez, M. C.; Tarnopolsky, M. A. Patients with dystrophinopathy show evidence of increased oxidative stress. Free Radic. Biol. Med. 34:1217-1220; 2003.

[71] Nakae, Y.; Stoward, P. J.; Kashiyama, T.; Shono, M.; Akagi, A.; Matsuzaki, T.; Nonaka, I. Early onset of lipofuscin accumulation in dystrophin-deficient skeletal muscles of DMD patients and mdx mice. J. Mol. Histol. 35:489-499; 2004.

[72] Disatnik, M. H.; Dhawan, J.; Yu, Y.; Beal, M. F.; Whirl, M. M.; Franco, A. A.; Rando, T. A. Evidence of oxidative stress in mdx mouse muscle: studies of the pre-necrotic state. J. Neurol. Sci. 161:77-84; 1998.

[73] Rando, T. A. Oxidative stress and the pathogenesis of muscular dystrophies. Am. J. Phys. Med. Rehabil 81:S175-186; 2002.

[74] Dorchies, O. M.; Wagner, S.; Vuadens, O.; Waldhauser, K.; Buetler, T. M. Kucera, P.; Ruegg, U. T. Green tea extract and its major polyphenol (-)-epigallocatechin gallate improve muscle function in a mouse model for Duchenne muscular dystrophy. Am. J. Physiol. Cell Physiol 290:C616-C625; 2006.

[75] Buetler, T. M.; Renard, M.; Offord, E. A.; Schneider, H.; Ruegg, U. T. Green tea extract decreases muscle necrosis in mdx mice and protects against reactive oxygen species. Am. J. Clin. Nutr. 75:749-753; 2002.

[76] Dorchies, O. M. Wagner, S.; Buetler, T. M.; Ruegg, U. T. Protection of dystrophic muscle cells with polyphenols from green tea correlates with improved glutathione balance and increased expression of 67LR, a receptor for (-)-epigallocatechin gallate. Biofactors 35:279-294; 2009.

[77] Nakae, Y.; Hirasaka, K.; Goto, J.; Nikawa, T.; Shono, M.; Yoshida, M.; Stoward, P. J. Subcutaneous injection, from birth, of epigallocatechin-3-gallate, a component of green tea, limits the onset of muscular dystrophy in mdx mice: quantitative histological, immunohistochemical and electrophysiological study. Histochem. Cell Biol 129:489-501; 2008.

[78] Messina, S.; Bitto, A.; Aguennouz, M.; Minutoli, L.; Monici, M. C.; Altavilla, D. Squadrito, F.; Vita, G. Nuclear factor kappa-B blockade reduces skeletal muscle degeneration and enhances muscle function in Mdx mice. Exp. Neurol. 198:234-241; 2006

[79] Burdi, R.; Rolland, J. F.; Fraysse, B.; Litvinova, K.; Cozzoli, A.; Giannuzzi, V.; Liantonio, A.; Camerino, G. M.; Sblendorio, V: Capogrosso, R. F. Palmieri, B.; Andreetta, F.; Confalonieri, P.; De Benedictis, L.; Montagnani, M.; De Luca, A Multiple pathological events in exercised dystrophic mdx mice are targeted by 
pentoxifylline: outcome of a large array of in vivo and ex vivo tests. J. Appl. Physiol. 106:1311-1324; 2009.

[80] Buyse, G. M.; Van der Mieren, G.; Erb, M.; D’Hooge, J.; Herijgers, P.; Verbeken, E.; Jara, A.; Van Den Bergh, A.; Mertens, L.; Courdier-Fruh, I.; Barzaghi, P.; Meier, T. Long-term blinded placebo-controlled study of SNT-MC17/idebenone in the dystrophin deficient mdx mouse: cardiac protection and improved exercise performance. Eur. Heart J. 30:116-124; 2009.
[81] Radley, H. G.; De Luca, A.; Lynch, G. S.; Grounds, M. D. Duchenne muscular dystrophy: focus on pharmaceutical and nutritional interventions. Int. J. Biochem. Cell Biol. 39:469-477; 2007.

[82] Hibaoui, Y.; Reutenauer-Patte, J.; Patthey-Vuadens, O.; Ruegg, U. T.; Dorchies, O. M. Melatonin improves muscle function of the dystrophic mdx5Cv mouse, a model for Duchenne muscular dystrophy. J. Pineal Res. 51:163-171; 2011. 